INFORMASI: Kajian Ilmu Komunikasi - ISSN (p) o126-0650; ISSN (e) 2502-3837

Vol. 48, No. 1 (2018), pp.109-124. doi: http://dx.doi.org/10.21831/informasi.v48i1.20203

\title{
ANALISIS BINGKAI PEMBERITAAN AKSI BELA ISLAM 2 DESEMBER 2016 (AKSI 212) DI MEDIA MASSA BBC (INDONESIA) \& REPUBLIKA
}

\author{
Abidatu Lintang Pradipta \\ abidatulintang.2017@student.uny.ac.id \\ Nadya Warih Nur Hidayah \\ nadyawarih2017@student.uny.ac.id \\ Afifah Nafiatun Annisa Haya \\ afifahnafiatun@student.uny.ac.id \\ Carissa Ervania \\ carissaervania@student.uny.ac.id \\ Deny Kristanto \\ denykristanto2017@student.uny.ac.id \\ Jurusan Ilmu Komunikasi Universitas Negeri Yogyakarta
}

\begin{abstract}
This article presents a framing analysis of news about Aksi Bela Islam 2 Desember 2016 (Aksi 212) which were reported by two local media: BBC Indonesia and Republika. Aksi 212 refers to a collective movement of Indonesian Muslim society which demands a lawsuit against the incumbent candidate of the 2017 DKI Jakarta governor election, Basuki Tjahaja Purnama or Ahok. The street demonstration that centered in the capital Jakarta received massive coverage from local and international media, reporting with various news frames. BBC Indonesia and Republika were among the big news houses that covered the event with their own distinctive perspectives. This is the reason that the authors attempt to conduct a framing analysis of the news about the issue reported by the two news organizations. Using Entman's (1993) framing model, the authors analyzed five news articles from the respective media. The results show that BBC Indonesia which belongs to the international news agency, $B B C$ UK tends to frame the Aksi 212 as a demonstration which has a negative connotation. On the other hand, Republika which is known for its Muslim target audience produces a news frame about the Aksi 212 in a more positive manner. This framing analysis provides a picture on how significant of an event is to be framed in a certain way by news agencies.
\end{abstract}

\section{Abstrak}

Artikel ini mengemukakan analisis pembingkaian (framing) terhadap pemberitaan Aksi Bela Islam 2 Desember 2016 (Aksi 212) yang disiarkan oleh dua media lokal: BBC Indonesia dan Republika. Aksi 212 yang merupakan puncak dari gerakan kolektif masyarakat Muslim Indonesia menuntut calon gubenur petahana Pilkada DKI Jakarta 
2017, Basuki Tjahaja Purnama atau Ahok, atas kasus penistaan agama. Aksi turun ke jalan yang berpusat di Ibu Kota Jakarta ini mendapat liputan meluas baik dari media lokal maupun internasional dengan bingkai pemberitaan (framing) yang berbeda-beda. $B B C$ Indonesia dan Republika termasuk media besar yang menumpukan pemberitaan terhadap aksi tersebut dengan sudut pandang yang berbeda. Ini yang melatarbelakangi penulis untuk melakukan analisis pembingkaian terhadap pemberitaan isu berkenaan dalam dua organisasi berita tersebut. Dengan menggunakan model pembingkaian Entman (1993), tim penulis menganalisis lima artikel berita dari masing-masing media. Hasil analisis menunjukkan bahwa BBC Indonesia yang merupakan rangkaian agensi berita internasional milik BBC Inggris cenderung membingkai Aksi 212 sebagai aksi demonstrasi yang mempunyai konotasi negatif. Di lain pihak, Republika yang dikenal sebagai penerbitan berita untuk masyarakat Muslim menghasilkan pembingkai berita tentang Aksi 212 dalam nada yang lebih positif. Hasil analisis pembingkaian ini memberi gambaran bagaimana signifikansi peristiwa tertentu mendorong agensi berita untuk membentuk perspektif tertentu melalui pembingkaian.

Keywords: Framing, Framing Theory, News, Aksi 212, Indonesia.

\section{PENDAHULUAN}

Aksi Bela Islam yang terjadi pada 2 Desember 2016 atau lebih dikenal sebagai Aksi 212 merupakan kulminasi dari gerakan turun ke jalan yang untuk menuntut proses hukum terhadap calon gubenur petahana DKI Jakarta, Jakarta Basuki Tjahaja Purnama atau yang lebih dikenal sebagai Ahok. Gerakan masif berpusat di halaman Monumen Nasional (Monas) ini dihadiri oleh umat Muslim dari berbagai kalangan baik dari Jakarta maupun luar Jakarta (Detiknews, 2016). Wakil Ketua Gerakan Nasional Pengawal Fatwa Majelis Ulama Indonesia (GNPF MUI), Zaitun Rasmin menyebutkan bahwa demo yang diisi dengan orasi dan doa bersama ini dihadiri sekitar tiga juta peserta (Rozie, 2016). Gerakan Aksi 212-yang didahului dengan aksi unjuk rasa pada 4 November 2016-dipicu oleh kemarahan kolektif masyarakat Islam khususnya di Jakarta yang mempermasalahkan penggunaan surat AlMaidah ayat 51 dalam kampanye Ahok di Kepulauan Seribu (Simanjutak, 2016). Ahok dianggap telah menistakan agama Islam karena menyebut bahwa pemilih beragama Islam dalam Pilihan Gubenur (Pilgub) DKI Jakarta "dibohongin dengan Al Maidah" yang dibuktikan dalam sebuah video tular (Abdul, 2016). Aksi ini mendapat peliputan berita yang besar dari berbagai media baik dari dalam dan luar negara.

Tidak dipungkiri bahwa pemberitaan Pilgub DKI Jakarta 2017 memang menarik perhatian seluruh masyarakt Indonesia apalagi unsur-unsur kampanye hitam (black campaign) yang menyangkut pasangan calon gubenur dan wakil gubenur. Pasangan calon gubenur dan wakil gubenur dalam Pilgub DKI Jakarta 2016 adalah: (1) Agus Harimurti Yudhoyono dan Sylviana Murni; (2) Basuki Tjahaja Purnama dan Djarot Saiful Hidayat; dan (3) Anies Baswedan dan Sandiaga Salahudin Uno (Liputan6.com, diakses pada 15 Desember 2017). Pasangan Anies-Sandi yang maju atas tiket PKS dan Gerindra memang mendapat dukungan penuh oleh umat Islam yang mempunyai sentimen negatif terhadap pasangan Ahok dan Djarot (Aziz, 2017). Tidak heran ketika Ahok terindikasi menistakan agama Islam, masyarakat Islam bereaksi dengan cukup keras sehingga tercetus gerakan Aksi Bela Islam.

Aksi Bela Islam 212 yang mampu mengumpulkan jutaan peserta hingga memadati Monas dan jalan-jalan utama di Jakarta pusat tentu tidak dilewatkan oleh media untuk membuat liputan. Kehadiran sejumlah toko nasional dan elit politik partai menjadikan aksi demonstrasi ini menarik untukdiliput dan didebatkan. Berbagai media baik media cetak, elektronik hingga dalam 
jaringan (daring), dari yang mainstream hingga underground mempunyai sudut pandang tersendiri dalam pemberitaan mereka. Sudut pandang ini yang kita kenal sebagai pembingkaian atau dalam teorinya disebut framing.

Penelitian dengan metode pembingkaian berita termasuk penelitian dalam bidang media dan komunikasi yang sering dilakukan untuk melihat kecenderungan berita membentuk opini masayarakat (Scheufele, 2006). Dalam konteks penelitian ini, pembingkaian berita dianggap masih relevan untuk dilakukan karena jelas berlaku dikotomi idea dan polarisasi masyarakat dalam dalam Pilgub DKI Jakarta 2017. Menanggapi Aksi 212, masyarakat juga terbagi menjadi dua antara yang pro dan kontra. Bahkan, muncul istilah kelompok Pancasilais yang mendukung keberagaman dan kelompok anti Pancasila atau anti Bhineka yang disematkan pada mereka yang bersuara keras atas nama agama tertentu terutama Islam (VOA-Islam, 2017). Ini bukti nyata bahwa dikotomi memang selalu mewarnai kehiduapn sosio-politik di Indonesia dan pemberitaan media terhadap peristiwa-peristiwa yang rawan dipolitisasi memang akan mendorong media untuk melakukan pembingkaian.

Nyatanya, organisasi media juga terpolarisasi menjadi beberapa kelompok sesuai dengan afiliasi politik dan kelompok beragama yang didukung. Ini dibuktikan dengan hasil penelitian ini yang menunjukkan bahwa media yang terangterang ditujukan untuk pembaca Muslim, yaitu Republika membingkai Aksi 212 dengan citra positif. Sementara $B B C$ Indonesia yang walaupun tidak terafiliasi dengan kelompok politik tertentu, mempunyai pandangan negatif dalam pemberitaan Aksi 212. Seperti apakah bentuk kecenderungan berita dalam pembingkaian oleh kedua media ini akan dibahas dalam konteks model pembingkaian Entman (1993).

\section{KAJIAN PUSTAKA}

Analisis pembingkaian

(framing) terhadap pemberitaan tentang isu tertentu telah banyak dilakukan. Isu Aksi 212 sendiri telah dikaji menggunakan analisis pembingkaian dengan fokus kajian berbedabeda. Sebagai contoh, Kurnia (2017) menggunakan model pembingkaian Entman (1993) untuk melihat kecenderungan berita mengenai Aksi Damai 212 pada media daring milik Kompas dan Republika. Hasilnya, kedua media daring ini fokus pada kasus penistaan agama yang dilakukan oleh gubenur non-aktif Ahok dan proses hukum yang berjalan (Kurnia, 2017). Kajian serupa dilakukan oleh Febrianti (2017) yang juga menganalisis pemberitaan Kompas dan Republika tentang kasus penggunaan ayat dalam surat Al-Maidah oleh Ahok. Walaupun yang difokuskan adalah kontrofersi AlMaidah 51, Dalam penelitiannya, Febrianti (2017) juga menganalisis berita-berita berkaiatan Aksi Damai 212. Febrianti (2017) menemukan bahwa Kompas menyampaikan berita yang cenderung negataif tentang Aksi 212, sedangkan Republika lebih menonjolkan tindakan salah yang dilakukan oleh Ahok.

Selain dua penelitian tersebut, analisis pembingkaian berita Aksi 212 pada Kompas dan Republika juga dilakukan oleh Mahesa (2017) yang menggunakan pendekatan teori Retorik. Dengan mencari unsur-unsur pembentuk Sintaksis, Skrip, Tematik, dan Retoris, Mahesa (2017) menemukan bahwa pemberitaan Aksi 212 oleh Republika lebih fokus pada unsur sintaksis yang menonjolkan kasus penistaan oleh Ahok, sedangkan Kompas menonjolkan unsur skrip dengan tumpuan cerita pada jalannya Aksi 212. Mahesa (2017) kemudian menyimpulkan bahwa kedua media tersebut membentuk konstruksi berita yang positif tentang Aksi 212. Hasil penelitian yang berbeda ini tentu saja dipengaruhi oleh penggunaa teori yang digunakan. Teori Retorik jelas berbeda dengan Teori Pembingkaian, terutama model pembingkaian oleh Entman (1993) yang memang ditujukan untuk mencari kecenderungan dalam pelaporan berita.

Satu lagi penelitian terhadap pemberitaan Aksi 212 yang menggunakan analisis pembingkaian Entman (1993) yaitu 
penelitian yang dilakukan oleh Amalia (2018). Berbeda dengan penelitian-penelitian yang telah dibahas di atas, penelitian Amalia (2018) hanya fokus pada satu media yaitu harian umum Republika. Temuan Amalia (2018) menunjukkan bahwa memang media yang mentargetkan pembaca Muslim tersebut membingkai Aksi Bela Islam yang diadakan pada 2 Desember 2016 adalah aksi yang positif.

Mengangkat isu yang sama serta menggunakan pendekatan teori pembingkaian Entman (1993), penelitian ini memilih sumber berita yang berbeda yaitu BBC Indonesia dan Republika. Penelitian sebelumnya (Febrianti, 2017; Kurnia, 2017; Mahesa, 2017) memilih media yang jelas kontra satu sama lain, di mana Kompas berafiliasi secara politik dengan pemerintah dan partai pendukung pasangan calon gurbenur dan wakil gurbenur Ahok-Djarot yaitu PDIP (Partai Demokrasi IndonesiaPerjuangan) dan Nasdem (Partai Nasional Demokrat), sedangkan Republika dinilai dekat dengan kekuatan politik bernuansa Islam seperti PKS (Partai Keadilan Sosial). Memilih kantor berita yang mewakili media internasional, yaitu $B B C$ Indonesia, yang tidak berafiliasi dengan partai manapun dan kantor berita lokal, Republika, hasil penelitian ini diharapkan memberikan sudut pandang lain tentang pembingkaian berita di Indonesia.

Selain media daring, analisis pembingkaian berita juga dilakukan terhadap media penyiaran. Contohnya, Zaelani dan Santana (2016) menggunakan pendekatan teori Pembingkaian Entman (1993) untuk menaganalisis konstruksi berita Aksi 212 pada INews TV dan Metro TV. Hasilnya, Zaelani dan Santana (2016: 183) menyimpulkan bahwa kedua stasiun televisi berita tersebut membingkai gerakan Aksi 212 sebagai sesuatu yang tidak sejalan dengan pemerintahan Jokowi.

Pada dasarnya, analisis pembingkaian terhadap pemberitaan tentang suatu isu tertentu dilajukan untuk mengatahui sudut pandang yang diambil oleh wartawan dalam menyikapi isu yang diberitakan. Ada beberapa model analisis pembingkaian seperti model yang dikembangkan oleh Goffman (1974); Gamson dan Mogdiliani (1989); Scheufele (1999), dan Entman (1993). Jika Scheufele (1999) melihat pembingkaian pada proses pembentukan bingkai, Gamson dan Mogdiliani (1989) melihat unsur pembingkaian dan penalaran verbal dan non-verbal dalam berita televisi. Berbeda dengan keduanya, model pembingkaian Entman (1993) dapat membantu peneliti untuk menganalisis bagian-bagian yang mempunyai unsur-unsur yang mengarah pada kecenderungan tertentu. Ini yang melatarbelakangi penulis menggunakan Teori Pembingkaian yang dikemukakan oleh Entman (1993).

\section{KERANGKA TEORI}

Teori framing yang digunakan pada makalah iniadalah model teoripembingkaian yang dibuat oleh Robert M. Entman. Entman menyatakan bahwa teori pembingkaian atau pembingkaian berita merupakan teori yang menonjolkan informasi-informasi tertentu dalam suatu bahasan. Tujuan dari dilakukannya pembingkaian ini adalah agar informasi-informasi tersebut dapat menjadi lebih menonjol, lebih bermakna, dan lebih mudah diingat oleh khalayak (Entman, 1993: 53). Entman menyatakan cara untuk menonjolkan informasi tersebut adalah dengan cara pengulangan (repetition) atau mengasosiasikan informasi tersebut dengan simbol yang familier secara kultural.

Framing atau pembingkaian berita ini akan mendorong orang untuk fokus kepada bagian-bagian tertentu dari keseluruhan peristiwa atau fenomena. Pembingkaian merupakan suatu cara untuk menyampaikan berita atau informasi melalui perspektif tertentu. Oleh karena itu, pembingkaian dapat memengaruhi cara seseorang dalam memahami suatu kejadian dan tindakan yang akan seseorang ambil atas kejadian tersebut. Hal tersebut membuat potret pembingkaian memiliki implikasi penting untuk komunikasi politik (Entman, 1993: 55). Paul D’Angelo (2002) menyatakan bahwa 
pembingkaian akan membentuk dialog publik tentang isu-isu politik. Selain itu, para individu juga memperbincangkan tentang isu-isu politik menggunakan mental frame mereka terhadap isu tersebut (Gamson, 1992, 1996). Pada dasarnya, individu akan cenderung menolak pendapat berita yang disajikan media jika berita tersebut tidak sejalan dengan pemikiran mereka terhadap isu yang ada. Hal tersebut menjelaskan mengapa isu-isu politik tidak akan dapat lepas dari framing atau pembingkaian. Termasuk berita yang dianalisis dalam makalah kali ini (berita mengenai aksi 212). Setiap media pasti akan memilih sudut pandang dan posisi tertentu dalam suatu isu politik. Latar belakang hal tersebut dapat disebabkan oleh faktor yang terkait dengan kepentingan dari media tersebut, maupun oleh modal dan kepemilikan media.

Para politisi yang mencari dukungan dituntut untuk bersaing antara satu sama lain. Tidak hanya itu, mereka juga bersaing dengan jurnalis agar mereka mendapat bagian untuk 'dibingkai' dalam berita (Entman, 1989; Riker, 1986). Para politisi atau orang-orang yang memiliki kepentingan tertentu memanfaatkan media sebagai salah satu cara untuk memeroleh dukungan dan legitimasi. Pembingkaian mempunyai peran yang terkait dengan kekuatan politik. Pada kenyataannya, pembingkaian memang dapat memengaruhi seseorang dalam membuat keputusan Keputusan tersebut dapat berupa dukungan atau penolakan terhadap suatu isu atau terhadap tindakan yang dilakukan mengenai isu tersebut. Entman menyatakan bahwa bingkai di dalam teks berita sendiri merupakan jejak dari kekuatan. Bingkai itu menunjukkan identitas aktor-aktor atau kepentingan-kepentingan yang bersaing untuk mendominasi teks tersebut (Entmant, 1993: 55).

Lalu bagaimana frame atau bingkai suatu berita dibentuk? Entman (1993) menyatakan terdapat alur atau tahapan-tahapan dalam proses pembingkaian, yaitu define problems (identifikasi masalah), diagnose causes (mendiagnosa atau menentukan masalah), make moral judgement (mengevaluasi penyebab dan dampaknya), dan yang terakhir adalah suggest remedies (menentukan cara penyelesaian, termasuk memprediksikan dampak dari penyelesaian tersebut).

Indikator pertama yaitu Define Problems atau mendefinisikan (mengidentifikasi) merupakan sudut pandang apa yang diterapkan oleh media dan posisi media dalamisu tertentu. Di sini, posisi media dalam suatu isu dapat bersifat pro, kontra, maupun netral. Setiap media akan mengambil posisi yang berbeda dan karenanya, framing atau pembingkaian di dalam sebuah berita dapat teridentifikasi. Indikator kedua yaitu Diagnose Causes adalah tahap di mana wartawan mendiagnosa penyebab masalah dan mengahdirkannya dalam paragraf penjelasan inti berita. Indikator selanjutnya adalah Make MoralJudgement atau menyusun penilaian moral dari peristiwa yang diberitakan. Setelah masalah teridentifikasi dan penyebabnya diketahui, maka yag selanjutnya dilakukan adalah membuat penilaian moral. Maksud dari membuat penilaian moral ini adalah penambahan substansi yang dapat memperkuat ideide yang telah diutarakan. Indikator yang terakhir adalah Suggest Remedies atau memberikan saran perbaikan terhadap masalah yang diberitakan. Dalam tahap ini, masalah di dalam suatu isu diberi saran atau alternatif penyelesaian sesuai dengan keinginan jurnalis atau wartawan dalam media yang bersangkutan. Penyelesaian yang diberikan akan tergantung kepada sudut pandang masalah yang diambil karena hal tersebut akan memengaruhi apa dan siapa yang menyebabkan masalah tersebut.

Entman (1993) menyatakan bahwa sebuah kalimat bisa saja berperan sebagai empat indikator yang telah diuraikan di atas, tetapi bisa saja di sebuah teks tidak ada satupun kalimat yang dapat berperan menjadi indikator. Pembingkaian di teks-teks tertentu juga tidak selalu mengikutsertakan keempat indikator tersebut.

\section{METODE PENELITIAN}

Penelitian ini merupakan analisis 
pembingkaian terhadap pemberitaan Aksi 212 oleh media daring yaitu Republika dan BBC Indonesia. Kami memilih dua media ini dengan pertimbangan bahwa $B B C$ Indonesia mewakili pihak yang kontra dan Republika mewakili pihak yang pro terhadap Aksi Bela Islam 212. Dari masing-masing media tersebut, kami memilih enam artikel berita untuk dianalisis. Berita tersebut kemudian dianalisis menggunakan model framing Entman (1993) dan disajikan dalam bentuk tabel. Tabel ini kemudian dilengkapi dengan uraian secara singkat mengenai berita yang dipublikasikan oleh kedua media tersebut. Artikel berita yang diambil adalah berita yang terbit mulai dari tanggal 25 November hingga 21 Februari 2017 pada laman web kantor berita masing-masing. Kesemua artikel ini kemudian dianalisis menggunakan model pembingkaian yang dikemukakan oleh Entman (1993).

Proses pengumpulan dan analisis data dilakukan antara tanggal 5 dan 19 Desember 2017. Pertama-tama, kami memilih artikel berita dari laman web masing-masing media. Setiap artikel yang dipilih kemudian dibaca secara keseluruhan untuk memperoleh gambaran umum tentang peristiwa yang diberitakan. Setelah itu, berita diuraikan menurut kode-kode analisis sesuai indikator dalam model pembingkaian Entman (1993). Indikatorindikator tersebut meliputi "pendefinisian masalah" (define problems), "pendiagnosisan penyebab masalah" (diagnose causes), "penyusunan penilaian moral" (make moral judgement), dan "pengusulan rekomendasi" (suggest remedies). Setelah dikodekan sesuai indikatornya, hasilnya diintepretasikan menurut kecenderungan berita sehingga didapat kesimpulan berupa bingkai.

\section{Sajian data analisis pembingkaian pemberitaan Aksi 212}

Seperti yang telah dijelaskan, analisis pembingkaian yang digunakan dalam penelitian ini adalah model pembingkaian Entman (1993). Artikel-artikel yang telah dipilih telah dianalisis dengan menggunakan kode-kode sesuai dengan indikator-indikator pada model pembingkaian tersebut. Total 12 artikel di mana enam artikel mewakili masing-masing media (BBC Indonesia dan Republika) telah dianalisis. Hasil dari analisis setiap artikel disajikan dalam table-tabel di bawah ini.

Tabel 1. Analisis pembingkaian artikel berita "Kontroversi Salat Jumat di Jalan Demo 2 Desember, Gus Mus, dan Permintaan Maaf" (BBC Indonesia, 25 November 2016)

\begin{tabular}{|l|l|}
\hline Indikator & Kutipan berita \\
\hline Define Problems & $\begin{array}{l}\text { Perdebatan terkait salat Jumat di jalanan bermula ketika wacana aksi yang } \\
\text { diklaim sebagai ‘bela Islam III' digulirkan oleh sejumlah ormas Islam. }\end{array}$ \\
\hline Diagnose Causes & $\begin{array}{l}\text { Di media sosial, ulama Nahdlatul Ulama Mustofa Bisri atau Gus Mus disorot } \\
\text { karena kicauannya yang menyebut bahwa salat Jumat di jalan adalah 'bid'ah } \\
\text { besar' -bidah adalah perbuatan menambah-nambah dalam ibadah. }\end{array}$ \\
\hline $\begin{array}{l}\text { Make Moral } \\
\text { Judgement }\end{array}$ & $\begin{array}{l}\text { Gerakan Nasional Pengawal Fatwa (GNPF) MUI tetap bersikukuh menggelar } \\
\text { salat Jumat di jalan protokol. } \\
\text { Kapolri Jenderal Tito Karnavian melarang demonstrasi apabila menutup Jalan } \\
\text { Sudirman dan Jalan MH Thamrin. } \\
\text { Ketua Umum Pengurus Besar Nahdlatul Ulama Said Aqil menegaskan pihaknya } \\
\text { telah mengeluarkan fatwa bahwa salat Jumat di jalan tidak sah dan 'bahkan } \\
\text { bisa haram jika menggangu ketertiban umum dan masalah sosial'. }\end{array}$ \\
\hline Suggest Remedies & $\begin{array}{l}\text { Gus Sholah mengatakan dirinya 'tidak membolehkan shalat jum'at di jalan, } \\
\text { boleh kalau mesjid sudah tidak bisa menampung. }\end{array}$ \\
\hline
\end{tabular}


Tabel 2. Analisis pembingkaian artikel berita “Aksi Demo 411, 212, dan 'Efek Trauma' yang Membayangi Pengusaha” ( $B B C$ Indonesia, 1 Desember 2016)

\begin{tabular}{|l|l|}
\hline Indikator & Kutipan berita \\
\hline Define Problems & $\begin{array}{l}\text { Gelombang kepergian para pengusaha untuk menghindari aksi demo 2 } \\
\text { Desember, sebagai aksi lanjutan dari 4 November lalu, sudah terjadi sejak } \\
\text { 23 November lalu. }\end{array}$ \\
\hline Diagnose Causes & $\begin{array}{l}\text { Sebagian pengusaha waswas menghadapiaksi 212 atau peristiwa 2 Desember } \\
\text { di Monas nanti yang, belajar dari unjuk rasa 4 November, menimbulkan } \\
\text { trauma bagi sebagian pengusaha keturunan Tionghoa dan memilih keluar } \\
\text { Jakarta. }\end{array}$ \\
\hline Make Moral Judgement & $\begin{array}{l}\text { Ade Sudradjat menilai bahwa bagi para pengusaha ini, unjuk rasa yang } \\
\text { mengerahkan massa berlebihan untuk memberikan daya tekan pada } \\
\text { pemerintah selalu menimbulkan efek trauma yang lebih besar, terutama } \\
\text { terkait kerusuhan 1998. }\end{array}$ \\
\hline Suggest Remedies & - \\
\hline
\end{tabular}

Tabel 3. Analisis pembingkaian artikel berita "Tujuh Juta atau 500.000? Ketika Media Sosial Berdebat Soal Jumlah Peserta Aksi 212 di Monas” (BBC Indonesia, 5 Desember 2016)

\begin{tabular}{|c|c|}
\hline Indikator & Kutipan berita \\
\hline Define Problems & $\begin{array}{l}\text { Jumlah peserta aksi menjadi isu sensitif yang dalam beberapa hari terakhir } \\
\text { bisa memicu orang di media sosial mengumpat dan bersikap nyinyir. } \\
\text { Berbagai pandangan yang berbeda diulas dalam blog, unggahan Facebook, } \\
\text { hingga media massa dengan angka yang berbeda-beda -dan bahkan } \\
\text { terlampau jauh perbedaannya. }\end{array}$ \\
\hline Diagnose Causes & $\begin{array}{l}\text { Gerakan Nasional Pengawal Fatwa MUI (GNPF-MUI) yang menjadi } \\
\text { penyelenggara aksi mengklaim bahwa aksi itu diikuti oleh } 7,5 \text { juta orang. } \\
\text { Tidak diperoleh lebih jauh bagaimana mereka mencapai kesimpulan } \\
\text { tersebut. Sementara sejumlah analisa, menyebut jumlahnya ada di kisaran } \\
\text { 50o.ooo orang. }\end{array}$ \\
\hline Make Moral Judgement & $\begin{array}{l}\text { Salah satu ulasan yang banyak dibahas adalah sebuah blog yang dibuat oleh } \\
\text { mahasiswa doktoral asal Indonesia yang bersekolah di Universitas Oxford, } \\
\text { Inggris, Muhammad Firmansyah Kasim. Dengan perhitungan matematis, } \\
\text { mahasiswa bidang fisika ini menghitung luasan jalan dari kawasan Tugu } \\
\text { Tani, Monas, hingga Jalan Thamrin dan memprediksi berapa orang yang } \\
\text { bisa muat dalam luasan itu. } \\
\text { "Dengan skala yang sama dengan sebelumnya, tiga orang per meter persegi, } \\
\text { estimasinya adalah sekitar } 757.840 \text { orang dalam aksi tersebut. Jika kita } \\
\text { menggunakan hitungan dua orang per meter persegi seperti sebelumnya, } \\
\text { ada sekitar } 505.227 \text { orang," katanya. }\end{array}$ \\
\hline Suggest Remedies & \\
\hline
\end{tabular}

Tabel 4. Analisis pembingkaian artikel berita "Dengan 212, Umat Islam 'Ingin Berkuasa lewat Pilkada, Pemilu dan Pilpres”" (BBC Indonesia, 1 Desember 2016)

\begin{tabular}{|l|l|}
\hline Indikator & Kutipan berita \\
\hline Define Problems & $\begin{array}{l}\text { Rangkaian acara alumni } 212 \text { itu kini terang-terangan diakui sebagai acara } \\
\text { politik, meskipun sebelumnya ada sebagian anggota panitia reuni yang } \\
\text { membantahnya. }\end{array}$ \\
\hline
\end{tabular}




\begin{tabular}{|l|l|}
\hline Diagnose Causes & $\begin{array}{l}\text { "Karena agenda mereka sebenarnya sudah selesai. Kalau agenda utamanya } \\
\text { menjatuhkan Ahok, memberhentikan Ahok sebagai gubernur, itu sudah } \\
\text { tercapai. Nah, sekarang mereka teruskan dengan demo-demo dan kelihatan } \\
\text { terus akan berkelanjutan. Itu sudah gerakan politik, bukan gerakan } \\
\text { keagamaan," kata Profesor Qasim. }\end{array}$ \\
\hline Make Moral Judgement & $\begin{array}{l}\text { Penegasan bahwa acara reuni } 212 \text { bermuatan politik disampaikan oleh } \\
\text { pembina presidium alumni } 212 \text { yang juga menjadi anggota tim advokasi } \\
\text { Gerakan Nasional Pengawal Fatwa- MUI, Kapitra Ampera, kepada BBC } \\
\text { Indonesia, Jumat (o1/12). } \\
\text { "Dan ini politik umat Islam, dan umat Islam sekarang ingin berkuasa } \\
\text { melalui jalur-jalur konstitusional, melalui pemilu, melalui pilkada dan } \\
\text { melalui pilpres." }\end{array}$ \\
\hline Suggest Remedies & \\
\hline
\end{tabular}

Tabel 5. Analisis pembingkaian artikel berita "Aksi 212: Rizieq Shihab Datang dan Menyeru 'Penjarakan Ahok”" (BBC Indonesia, 21 Februari 2017)

\begin{tabular}{|l|l|}
\hline Indikator & Kutipan berita \\
\hline Define Problems & $\begin{array}{l}\text { Saat berorasi di hadapan ribuan peserta aksi, Rizieq kembali menyuarakan } \\
\text { seruan pada beberapa unjuk rasa sebelumnya, yaitu penjarakan Gubernur } \\
\text { DKI Jakarta, Basuki Tjahaya Purnama alias Ahok. }\end{array}$ \\
\hline Diagnose Causes & $\begin{array}{l}\text { Dalam orasi, salah satu pimpinan aksi menyerukan Ahok ditahan atas } \\
\text { tuduhan penistaan agama Islam. }\end{array}$ \\
\hline Make Moral Judgement & $\begin{array}{l}\text { "Kalau Ahok tidak ditahan juga, maka jangan kaget kalau Jokowi yang } \\
\text { kita tumbangkan. Sudah tiga kali diingatkan dengan damai, jika tidak } \\
\text { didengarkan maka kita revolusi," ujar sang orator, yang disambut pekikan } \\
\text { takbir para peserta. }\end{array}$ \\
\hline Suggest Remedies & - \\
\hline
\end{tabular}

Tabel 6. Analisis pembingkaian artikel berita "Apakah aksi 411 dan 212 membuat FPI menjadi 'besar'?” (BBC Indonesia, 2 Desember 2016)

\begin{tabular}{|l|l|}
\hline Indikator & Kutipan berita \\
\hline Define Problems & $\begin{array}{l}\text { FPI -yang merupakan motor unjuk rasa berlabel Gerakan nasional pengawal } \\
\text { fatwa Majelis Ulama Indonesia (GNPF-MUI) dalam kasus dugaan penistaan } \\
\text { agama dengan tersangka Gubernur DKI Jakarta nonaktif, Basuki Tjahaja } \\
\text { Purnama -dianggap mampu menggalang massa yang jumlahnya mencapai } \\
\text { ratusan ribu. }\end{array}$ \\
\hline Diagnose Causes & $\begin{array}{l}\text { Pengamat Islam dan staf pengajar Universitas Paramadina, Jakarta, Budhy } \\
\text { Munawar Rahman menganggap membanjirnya dukungan terhadap aksi } \\
\text { massa yang dimotori FPI itu tidak terlepas dari kebijakan pemerintah } \\
\text { yang selama ini terkesan tidak tegas terhadap keberadaan dan sejumlah } \\
\text { tindakan ormas tersebut. } \\
\text { Anggapan Budhy merujuk pada sejumlah tindak kekerasan dan sikap } \\
\text { anti toleran yang pernah dilekatkan pada FPI, tetapi hampir tidak pernah } \\
\text { disikapi serius oleh pemerintah termasuk tuntutan agar FPI dibubarkan. }\end{array}$ \\
\hline Make Moral Judgement & $\begin{array}{l}\text { Bagaimanapun, pengamat Islam dan staf pengajar Universitas } \\
\text { Paramadina, Jakarta, Budhy Munawar Rahman, mengatakan, tindakan } \\
\text { mengaitkan persoalan agama dengan masalah politik praktis merupakan } \\
\text { tindakan yang sangat berbahaya. }\end{array}$ \\
\hline
\end{tabular}




\begin{tabular}{|l|l|}
\hline Suggest Remedies & $\begin{array}{l}\text { "Lebih mampu mendidik, mengembangkan kapasitas anggotanya untuk } \\
\text { bisa membedakan mana masalah politik dan agama yang sesungguhnya, } \\
\text { dan kematangan untuk bisa berpolitik tanpa harus menggunakan isu } \\
\text { agama, itu sangat penting," katanya. }\end{array}$ \\
\hline
\end{tabular}

Tabel 7. Analisis pembingkaian artikel berita "Menghitung Jumlah Peserta 212" (Republika, 5 Desember 2016)

\begin{tabular}{|l|l|}
\hline Indikator & Kutipan berita \\
\hline Define Problems & $\begin{array}{l}\text { Berdasarkan fakta visual, aksi } 212 \text { lebih banyak dari aksi 411. Maka jumlah } \\
\text { pesertanya pasti lebih banyak dari } 2 \text { juta orang. Berdasarkan perhitungan } \\
\text { cara densitas area, bilangan maksimal yang diperoleh berdasarkan } \\
\text { perhitungan komunitas drone adalah 3.987.072. Sedangkan berdasarkan } \\
\text { keyakinan bahwa tidak ada yang bisa menghitung secara tepat jumlahnya, } \\
\text { maka berdasarkan asas manfaat saya lebih suka menyebutkan kalau peserta } \\
\text { aksi 212 ini adalah 5.513.212 orang. }\end{array}$ \\
\hline Diagnose Causes & $\begin{array}{l}\text { Sesungguhnya pasti akan banyak orang berbeda pendapat tentang jumlah } \\
\text { peserta aksi 212 ini dan pasti akan banyak bilangan yang ditampilkan untuk } \\
\text { menunjukkan jumlah peserta aksi 212. }\end{array}$ \\
\hline Make Moral Judgement & $\begin{array}{l}\text { jika secara visual orang melihat peserta aksi } 212 \text { jumlahnya } 3 \text { kali lipat lebih } \\
\text { dari aksi 411, maka akan muncul dugaan jumlah peserta aksi sekitar 7 juta } \\
\text { orang. }\end{array}$ \\
\hline Suggest Remedies & - \\
\hline
\end{tabular}

Tabel 8. Analisis pembingkaian artikel berita “Aksi 212 Bukti Kedewasaan Umat Islam” (Republika, 3 Desember 2016)

\begin{tabular}{|l|l|}
\hline Indikator & Kutipan berita \\
\hline Define Problems & $\begin{array}{l}\text { Aksi Bela Islam 2 Desember 2016 menjadi bukti kedewasaan dan kesantunan } \\
\text { umat Islam dalam berdemokrasi. Aksi ini bisa menjadi teladan bagi bangsa } \\
\text { bahkan dunia. }\end{array}$ \\
\hline Diagnose Causes & $\begin{array}{l}\text { Ia (Jazuli Juwaini, Ketua Fraksi PKS DPR) mengatakan apresiasi layak } \\
\text { diberikan kepada panitia yang mampu mengelola aksi dengan sangat baik. }\end{array}$ \\
\hline Make Moral Judgement & $\begin{array}{l}\text { "Ini bisa menjadi teladan bagi bangsa bahkan dunia. Dengan jumlah massa } \\
\text { yang luar biasa besar (hingga mencapai } 4 \text { juta menurut sejumlah media, } \\
\text { red), aksi ini menjadi yang terbesar sepanjang sejarah, tapi semuanya tertib } \\
\text { rapi, sangat elegan. Bahkan peserta aksi berlomba-lomba mengingatkan } \\
\text { agar tidak menginjak taman dan membersihkan sampah begitu aksi usai," } \\
\text { kata Jazuli. }\end{array}$ \\
\hline Suggest Remedies & $\begin{array}{l}\text { Aksi yang super damai ini juga membuktikan bahwa pendekatan persuasif, } \\
\text { arif dan bijak seperti inilah yg harusnya dikedepankan oleh penguasa dalam } \\
\text { menghadapi persolan di masyarakat. }\end{array}$ \\
\hline
\end{tabular}

Tabel 9. Analisis pembingkaian artikel berita "Alhamdullilah, Rezeki dari Aksi Damai 212" (Republika, 2 Desember 2016)

\begin{tabular}{|l|c|}
\hline Indikator & Kutipan berita \\
\hline Define Problems & "Diborong Rp 3 juta untuk 200 porsi, alhamdulillah rezeki, biasan- \\
& ya sehari cuman dapet Rp 200 ribu sampai Rp 50o ribu," ungkap \\
& perempuan yang biasa berjualan di Jalan Blora, Menteng, Jakarta \\
& Pusat itu kepada Republika, Jumat (2/11). \\
\hline
\end{tabular}




\begin{tabular}{|c|c|}
\hline Diagnose Causes & $\begin{array}{l}\text { Ida (45 tahun) salah seorang pedagang ketupat sayur mengung- } \\
\text { kapkan sejak pukul o3.oo WIB gerobak miliknya sudah diborong } \\
\text { sebanyak } 200 \text { porsi untuk memberikan sarapan gratis. }\end{array}$ \\
\hline Make Moral Judgement & - \\
\hline Suggest Remedies & - \\
\hline
\end{tabular}

Tabel 10. Analisis pembingkaian artikel berita "Kriminalisasi Ulama dan Puluhan Juta Rekening Umat (Kebangkitan Umat 4)" (Republika, 2 Februari 2017)

\begin{tabular}{|l|l|}
\hline Indikator & Kutipan berita \\
\hline Define Problems & $\begin{array}{l}\text { Perpecahan dan atau upaya pecah belah terhadap umat Islam begitu kental } \\
\text { dirasakan di negeri mayoritas Muslim terbesar di dunia. Pascaaksi super } \\
\text { damai 212', banyak sekali pihak yang ketakutan. Seolah muak melihat } \\
\text { persatuan Muslim Indonesia. }\end{array}$ \\
\hline Diagnose Causes & $\begin{array}{l}\text { lembaga MUI dihinakan, ditolak, dan dituduh sedemikan rupa. } \\
\text { Terlebih FPI dan GNPF MUI, dua kekuatan umat yang dikenal } \\
\text { sebagai inisiator gerakan aksi 212. }\end{array}$ \\
\hline Make Moral Judgement & - \\
\hline Suggest Remedies & - \\
\hline
\end{tabular}

Tabel 11. Analisis pembingkaian artikel berita "Jokowi: Aksi 2/12 Itu Doa Bersama, Bukan Demo" (Republika, 30 November 2016)

\begin{tabular}{|l|l|}
\hline Indikator & Kutipan berita \\
\hline Define Problems & $\begin{array}{l}\text { Presiden mempersilakan ummat dari daerah datang ke Jakarta untuk } \\
\text { berpartisipasi dalam aksi asal patuh pada komitmen yang telah dibuat. }\end{array}$ \\
\hline Diagnose Causes & $\begin{array}{l}\text { "Ya kan mereka semangat. Yang penting nanti dalam aksi damai itu tidak } \\
\text { ada rusuh. Karena ini kan namanya doa bersama, bukan demo," kata } \\
\text { Presiden di teras belakang Istana Merdeka, Rabu (30/11). }\end{array}$ \\
\hline Make Moral Judgement & $\begin{array}{l}\text { Terkait doa bersama, Jokowi mengatakan, ribuan massa yang hadir nanti } \\
\text { diharapkan memanjaatkan doa untuk kebaikan bangsa Indonesia. Secara } \\
\text { khusus, Presiden berharapagar Indonesia tetap damai, makin makmur dan } \\
\text { sejahtera. }\end{array}$ \\
\hline Suggest Remedies & - \\
\hline
\end{tabular}

Tabel 12. Analisis pembingkaian artikel berita "Framing Media Barat Terhadap Aksi Damai 212" (Republika, 4 Desember 2016)

\begin{tabular}{|l|l|}
\hline Indikator & Kutipan berita \\
\hline Define Problems & $\begin{array}{l}\text { Benar bahwa ada kekerasan yang membonceng doktrin Islam, ada } \\
\text { aksi terorisme yang menyatut simbol-simbol Islam, ada ideologi yang } \\
\text { mencampur-adukkan prinsip-prinsip dalam Islam. } \\
\text { Tapi melakukan framing secara parsial dapat menimbulkan bias dan } \\
\text { kerancuan dalam interpretasi suatu peristiwa. }\end{array}$ \\
\hline Diagnose Causes & $\begin{array}{l}\text { Para peneliti dari Australia yang menulis buku Media Framing ofthe Muslim } \\
\text { World, yaitu Halim Rane, Jacqui Ewart, dan John Martinkus, menyatakan } \\
\text { mayoritas media barat melakukan framing terhadap dunia Islam dengan } \\
\text { narasi kekerasan, fanatisme, ekstremisme, dan memusuhi peradaban } \\
\text { barat. }\end{array}$ \\
\hline
\end{tabular}




\begin{tabular}{|l|l|}
\hline Make Moral Judgement & $\begin{array}{l}\text { Media-media ini cenderung mengaburkan esensi dari suatu kejadian dan } \\
\text { mem-framing dengan angle semau mereka-yang bahkan terkadang jauh } \\
\text { dari realita. Framing dan agenda setting adalah kata kunci dari perilaku } \\
\text { media-media ini. }\end{array}$ \\
\hline Suggest Remedies & $\begin{array}{l}\text { Yang bisa dilakukan adalah melawan dengan citizen journalism. } \\
\text { Membangun kesadaran sosial untuk memberikan informasi yang benar } \\
\text { melalui media alternatif yang bisa dipertanggungjawabkan. }\end{array}$ \\
\hline
\end{tabular}

PEMBAHASAN HASIL ANALISIS

\section{Pembingkaian pemberitaan Aksi 212}

Dari sajian di atas, dapat diketahu uraian-uraian berita yang mengandung unsur pembingkaian Entman (1993). Setelah diketahui uraian tersebut, dapat disimpulkan kecenderungan konstruksi berita oleh kedua media yang dipilih dalam penelitian ini. Yang pertama, ditemukan bahwa pembingkaian terhadapaksi 212 oleh BBC Indonesia ternyata cenderung negatif. Sebaliknya, dan sudah dapat diprediksi, Republika memberukan citra positif dalam pelaporan berita tentang Aksi 212.

\section{Pembingkaian negatif terhadap Aksi 212 oleh BBC Indonesia}

Posisi BBC (Indonesia) mengenai isu Aksi 212 cenderung mengarah kepada ketidaksetujuan (kontra). BBC seakan menunjukkan kesan negatif mengenai Aksi 212 tersebut. Hal tersebut terlihat dari penggunaan kata 'demonstrasi' untuk menggambarkan aksi tersebut. Berikut ini merupakan kutipan dari penggunaan kata tersebut.

Pihak kepolisian menyebut bahwa aksi unjuk rasa boleh dilakukan asal tidak mengganggu kepentingan publik. Kapolri Jenderal Tito Karnavian melarang demonstrasi apabila menutup Jalan Sudirman dan Jalan MH Thamrin. ("Kontroversi Salat Jumat di Jalan Demo 2 Desember, Gus Mus, dan Permintaan Maaf", 25 November 2016).

$\mathrm{BBC}$ juga cenderung lebih banyak memasukkan pernyataan-pernyataan dari beberapa orang yang menentang Aksi 212 karena aksi tersebut dianggap merugikan. Berikut merupakan kutipan dari beberapa pernyataan yang disebutkan dalam berita BBC.

Gelombang kepergian para pengusaha ini, menurut Ade, sudah terjadi sejak 23 November lalu. Dan sebagai dampaknya, aktivitas retail pembelian bahan baku serta penjualan bahan jadi tekstil pun melambat sehingga pengendapan barang terjadi di pabrik dan menimbulkan kerugian ekonomi. ("Aksi Demo 411, 212, dan 'Efek Trauma' yang Membayangi Pengusaha," 1 Desember 2016)

Di media sosial, ulama Nahdlatul Ulama Mustofa Bisri atau Gus Mus disorot karena kicauannya yang menyebut bahwa salat Jumat di jalan adalah 'bid'ah besar' -bidah adalah perbuatan menambah-nambah dalam ibadah. ("Kontroversi Salat Jumat di Jalan Demo 2 Desember, Gus Mus, dan Permintaan Maaf," 25 November 2016).

Terkait dengan jumlah peserta Aksi 212, BBC pun cenderung bersikap skeptis. Walaupun begitu, masih terdapat kalimatkalimat dalam berita yang sifatnya netral.

Tapi, terlepas semua perdebatan di media sosial tampaknya banyak orang sepakat bahwa aksi 2 Desember di Monas menjadi salah satu salat Jumat dengan peserta terbanyak di Indonesia. ("Tujuh Juta atau 500.ooo? Ketika Media Sosial Berdebat Soal Jumlah Peserta Aksi 212 di Monas," 5 Desember 2016).

"Kenapa kalau umat Islam melakukan kegiatan lalu dituding itu politik yang konotasinya negatif?" ("Dengan 212, Umat Islam 'Ingin Berkuasa lewat Pilkada, Pemilu Dan Pilpres'," 1 Desember 2017). 
Selain itu juga nampak sekali BBC ingin menampilkan pesan bahwa umat yang berdemo membawa kepentingan politik. Kepentingan tersebut tak lepas dari gelaran pemilihan kepala daerah (pilkada), pemilihan umum (pemilu), serta pemilihan presiden (pilpres). Berikut kutipan yang senada dengan pernyataan tsb.

"Untuk mengkonsolidasikan umat Islam sehingga menimbulkan kesadaran agar memilih pemimpin, baik kepala daerah, maupun di legislatif melalui pemilu maupun pilpres di eksekutif melalui pemilihan presiden untuk memilih umat Islam yang berkualitas memimpin republik ini, memimpin daerah dan memimpin DPR. Dan ini politik," jelasnya dalam wawancara melalui telepon.

"Dan ini politik umat Islam, dan umat Islam sekarang ingin berkuasa melalui jalur-jalur konstitusional, melalui pemilu, melalui pilkada dan melalui pilpres."("Dengan 212, Umat Islam 'Ingin Berkuasa lewat Pilkada, Pemilu Dan Pilpres,'” 1 Desember 2017).

Dengan diksi 'menguasai' (pada judul salah satu berita) yang mengesankan bahwa suatu hal yang negatif, bahkan dapat dikatakan cukup frontal untuk sebuah judul berita. Meskipun yang menjadi bahasan mengenai 'reuni' aksi 212, tetapi highlight justru lebih kepada suksesi aksi tahun sebelumnya (2016).

"Karena agenda mereka sebenarnya sudah selesai. Kalau agenda utamanya menjatuhkan Ahok, memberhentikan Ahok sebagai gubernur, itu sudah tercapai. Nah, sekarang mereka teruskan dengan demo-demo dan kelihatan terus akan berkelanjutan. Itu sudah gerakan politik, bukan gerakan keagamaan," kata Profesor Qasim. ("Dengan 212, Umat Islam 'Ingin Berkuasa lewat Pilkada, Pemilu Dan Pilpres,"” 1 Desember 2017).

Selain itu BBC cenderung mengangkat hal yang bernada kebencian dalam beritanya. Apalagi terdapat nama seorang Rizieq Shihab yang dikenal cukup kontroversial. Bahkan
BBC cukup berani mengutip orasi dari orator (Rizieq Shihab) yang menggambarkan kebencian yang menggebu.

"Kalau Ahok tidak ditahan juga, maka jangan kaget kalau Jokowi yang kita tumbangkan. Sudah tiga kali diingatkan dengan damai, jika tidak didengarkan maka kita revolusi," ujar sang orator, yang disambut pekikan takbir para peserta. ("Aksi 212: Rizieq Shihab datang dan menyeru 'penjarakan Ahok,' 21 Februari 2017).

BBC juga tak luput mengangkat 'motor' dari aksi ini, yaitu Front Pembela Islam (FPI). FPI banyak diberitakan media nasional adalah sebuah ormas yang sering berbuat anarkisme dan intoleran. FPI juga terlanjur mendapat banyak citra buruk di masyarakat. BBC justru malah mengangkat hal yang seolah-olah anarkisme dan intoleransi semakin besar dengan eksistensi FPI yang membesar. Dengan mengutip pernyataan tokoh yang menganggap FPI justru dibiarkan melakukan tindakan yang buruk tsb.

Pengamat Islam dan staf pengajar Universitas Paramadina, Jakarta, Budhy Munawar Rahman menganggap membanjirnya dukungan terhadap aksi massa yang dimotori FPI itu tidak terlepas dari kebijakan pemerintah yang selama ini terkesan tidak tegas terhadap keberadaan dan sejumlah tindakan ormas tersebut.

Anggapan Budhymerujukpadasejumlah tindak kekerasan dan sikap anti toleran yang pernah dilekatkan pada FPI, tetapi hampir tidak pernah disikapi serius oleh pemerintah -termasuk tuntutan agar FPI dibubarkan. ("Apakah aksi 411 dan 212 membuat FPI menjadi 'besar'?" 2 Deesember 2017).

Selain itu organisasi keagamaan (Islam) terbesar di Indonesia (NU dan Muhammadiyah) juga terkesan resistant terhadap yang dilakukan oleh FPI. Dengan kata lain tidak mendukung gerakan 212 tsb.

Sementara, Sekjen Pengurus Besar NahdlatulUlama(PBNU), HelmyFaishal Zaini mengatakan 'membesarnya' FPI 
tidak bisa ditimpahkan kesalahannya pada NU dan Muhammadiyah. Dia juga menolak bahwa organisasinya kecolongan. ("Apakah aksi 411 dan 212 membuat FPI menjadi 'besar'?" 2 Deesember 2017)

\section{Pembingkaian positif terhadap Aksi 212 oleh Republika}

Berkebalikan dari BBC, media Republika mengambil posisi sebagai pihak yang mendukung Aksi 212. Hal tersebut dibuktikan dengan pemberian citra positif terhadap Aksi 212. Berbeda dengan BBC, dari enam berita yang dianalisis di Republika, tidak ditemukan kata 'demonstrasi' untuk mengambarkan Aksi 212. Hal ini senada dengan apa yang dikatakan Presiden Joko Widodo mengenai aksi tersebut.

"Ya kan mereka semangat. Yang penting nanti dalam aksi damai itu tidak ada rusuh. Karena ini kan namanya doa bersama, bukan demo," kata Presiden di teras belakang Istana Merdeka, Rabu (30/11). ("Jokowi: Aksi 2/12 Itu Doa Bersama, Bukan Demo," 30 November 2016).

Sangat kontradiktif dengan BBC, aksi 212 digambarkan sebagai aksi yang damai dan tertib, tidak terdapat kerusuhan atau kekerasan di dalamnya. Bahkan sampai dikatakan 'super' damai. Tertulis bahwa Aksi 212 merupakan aksi yang dapat menjadi teladan bagi bangsa dan dunia. Pendeskripsian Aksi 212 di media Republika dapat dilihat dalam kutipan berikut.

Ketua Fraksi PKS DPR, Jazuli Juwaini mengapresiasi aksi super damai 212 yang berjalan dengan tertib dan damai. "Aksi super damai 212 benar-benar super. Sangat tertib, super damai, dan indah mengagumkan. Mereka tetap dalam barisan shaf yang rapi hingga tuntas acara. Lalu membubarkan diri sesuai waktu yang ditentukan," puji Jazuli dalam siaran pers yang diterima Republika.co.id, Sabtu (3/12).

Aksi yang super damai ini juga membuktikan bahwa pendekatan persuasif, arif dan bijak seperti inilah yg harusnya dikedepankan oleh penguasa dalam menghadapi persolan di masyarakat. ("Aksi 212 Bukti Kedewasaan Umat Islam", 2 Desember 2016)

Berkaitan dengan dugaan intoleransi dan intimidasi yang ada dalam aksi ini, terdapat kutripan yang membantah adanya hal buruk tersebut. Dengan penegasan bahwa aksi yang dilakukan jauh dari cara intimidasi dan kekerasan.

"Zaman moderen seperti sekarang sudah tidak relevan lagi mengunakan cara-cara intimidasi dan kekerasan dalam menghadapai dan menyelesaikan persoalan umat, rakyat, dan bangsa," kata Jazuli. ("Aksi 212 Bukti Kedewasaan Umat Islam," 2 Desember 2016)

Menyikapi dengan adanya dugaan penodaan agama, berbeda dengan $\mathrm{BBC}$ yang mengangkat kebencian dalam beritanya. Republika justru menampilkan kutipan yang bijak menanggapi kasus tersebut.

"Kita semua harus mengawal dan mengontrol Kejaksaan dalam menjalankan tugas dan fungsinya sambari kita do'akan agar Kejaksaan dapat bimbingan dari Allah untuk mengakan hukum dengan adil baik dan benar," ungkap Jazuli. ("Aksi 212 Bukti Kedewasaan Umat Islam," 2 Desember 2016).

Republika juga menegaskan bahwa aksi 212 ini mendapat dukungan dari banyak pihak. Termasuk di dalamnya ada para petinggi negara yang hadir. Hal tersebut sesuai dengan kutipan dalam salah satu berita.

Hadirnya Presiden dan Wakil Presiden beserta para menteri, yang bergabung dalam aksi dan sholat jumat menambah kesejukan aksi super damai yang benar-benar super ini. ("Aksi 212 Bukti Kedewasaan Umat Islam," 2 Desember 2016)

Republika juga mengambil perspektif bahwa Aksi 212 merupakan aksi yang membawa rezeki dan memperkuat secara 
finansial serta bukan aksi yang merugikan. Hal tersebut nampak dalam kutipan berikut.

Ida (45 tahun) salah seorang pedagang ketupat sayur mengungkapkan sejak pukul o3.0o WIB gerobak miliknya sudah diborong sebanyak 200 porsi untuk memberikan sarapan gratis. "Diborong $R p 3$ juta untuk 200 porsi, alhamdulillah rezeki, biasanya sehari cuman dapet $R p 200$ ribu sampai $R p$ 500 ribu," ungkap perempuan yang biasa berjualan di Jalan Blora, Menteng, Jakarta Pusat itu kepada Republika, Jumat (2/11). ("Alhamdullilah, Rezeki dari Aksi Damai 212'," 2 Desember 2016)

Kita patut berbahagia, pascaaksi Super Damai 212 terbentuk Koperasi Syariah 212. Koperasiitu sebagaitandakesadaran umat Islam bersatu. Tetapi, jika masih menggunakan jalan riba, sama halnya mengulang kesalahan serupa. Hal penting adalah substansinya, bukan namanya. ("Kriminalisasi Ulama dan Puluhan Juta Rekening Umat (Kebangkitan Umat 4)," 2 Februari 2017)

Mengenai jumlah peserta Aksi 212, Republika bersifat optimis. Media ini seakan tidak menghiraukan komentar-komentar yang beredar mengenai jumlah peserta yang dikatakan sebagian pihak 'tidak masuk akal'. Salah satu penulis di Republika yang membahas isu tersebut malah membuat angka unik yang memiliki makna tersendiri.

Sedangkan berdasarkan keyakinan bahwa tidak ada yang bisa menghitung secara tepat jumlahnya, maka berdasarkan asas manfaat saya lebih suka menyebutkan kalau peserta aksi 212 ini adalah 5.513.212 orang.

..... itu adalah perkiraan jumlah peserta Aksi Bela Islam Jilid 3 yang membela surat Al Maidah ayat 51 pada tanggal 2 Desember. ("Menghitung Jumlah Peserta 212," 5 Desember 2016).

Selain itu dampak dari aksi ini adalah banyaknya kriminalisasi terhadap ulama. Kriminalisasi ini dilakukan dengan bukti nyata banyak penolakan. Hal tersebut menunjukkan kesan bahwa banyak orang yang 'menolak' ajakan kebaikan dalam aksi 212.

Ulama dibunuh karakternya, ormas Islam bahkan sekelas lembaga MUI dihinakan, ditolak, dan dituduh sedemikan rupa. Terlebih FPI dan GNPF MUI, dua kekuatan umat yang dikenal sebagai inisiator gerakan aksi 212. Terbaru, dua kali dua ormas itu ditolak di Balikpapan, satu kali di Samarinda. ("Kriminalisasi Ulama dan Puluhan Juta Rekening Umat (Kebangkitan Umat 4)," 2 Februari 2017).

Aksi ini juga menjadi bahan pembingkaian oleh media barat. Kita semua mengetahui bahwa sentimen mengenai barat terhadap Islam cukup tinggi dan sangat sensitif. Media barat dalam Republika digambarkan melakukan 'usaha' untuk memperburuk citra aksi 212 dengan narasi buruk.

Lalu, bagaimana media-media barat merespons Aksi Damai 212? Para peneliti dari Australia yang menulis buku Media Framing of the Muslim World, yaitu Halim Rane, Jacqui Ewart, dan John Martinkus, menyatakan mayoritas media barat melakukan pembingkaian terhadap dunia Islam dengan narasi kekerasan, fanatisme, ekstremisme, dan memusuhi peradaban barat. ("Framing Media Barat Terhadap Aksi 212," 4 Desember 2016).

Dari banyak tantangan dan penolakan yang ada, umat Islam digambarkan sebagai umat yang heroik. Karena meski banyak upaya penggembosan dan sebagainya, aksi tersebut berjalan denngan lancar dan sangat besar. Hal ini sesuai dengan kutipan yang ada dalam salah satu berita Republika.

Ketua Dewan Penasihat Gerakan Nasional Pengawal Fatwa MUI (GNPFMUI), Habib Muhammad Rizieq Syihab, mengaku ada upaya-upaya untuk menggembosi aksi damai bela Islam jilid III (Aksi Damai 212). ("Lima Upaya Penggembosan Aksi Damai 212," 4 Desember 2016). 


\section{KESIMPULAN}

Dari beberapa tahapan pembingkaian mengenai analisis bingkai pemberitaan aksi bela islam 2 Desember 2016 (212) di media massa BBC (Indonesia) \& Republika dapat kita simpulkan lagi bahwa BBC (Indonesia) cenderung mengarah pada ketidaksetujuan (kontra) terhadap Aksi 212. Terlihat dari penggunaan kata 'demonstrasi' untuk menggambarkan aksi tersebut. BBC juga cenderung lebih banyak memasukkan pernyataan-pernyataan dari beberapa orang yang menentang aksi ini. Juga BBC menunjukkan sikap skeptis dengan 'kebesaran' aksi 212 yang digadang-gadang mencapai jutaan orang. Aksi ini juga dianggap terlalu bermuatan politis. Terdapat pula dalam judul yaitu kata'menguasai' yang memiliki diksi negatif. $\mathrm{BBC}$ cenderung mengangkat hal yang bernada kebencian dalam beritanya yang disampaikan seorang Rizieq Shihab. FPI yang terkesan 'memecah' persatuan juga diangkat dalam berita ini dengan mempertanyakan tingkat eksistensinya. NU dan Muhammadiyah yang merupakan organisasi Islam terbesar di Indonesia juga dianggap resistant dengan yang dilakukan FPI dalam memotori aksi tsb.

Berkebalikan dengan BBC, media Republika mengambil posisi sebagai pihak yang mendukung Aksi 212. Hal tersebut dibuktikan dengan tidak adanya kata demonstrasi. Presiden Indonesia Joko Widodo dalam pemberitaan Republika juga mengatakan aksi ini bukan demo, hanya doa bersama. penggambaran Aksi 212 sebagai aksi yang damai dan tertib, tidak terddapat kerusuhan atau kekerasan di dalamnya dan merupakan aksi yang dapat menjadi teladan bagi bangsa. Bahkan aksi ini dikatakan dengan 'super' damai. Serta adanya bantahan bahwa aksi ini intoleran, diskriminatif, intimidasi, dan kekerasan. Republika juga menunjukkan kebijaksanaan umat Islam dalam menghadapi kasus dugaan penodaan agama (tidak seperti BBC dimana umat Islam terkesan 'brutal'). Aksi ini diberitakan juga mendapat dukungan yang sangat banyak sampai pada tingkat pejabat negara. Klaim tentang jumlah peserta aksi yang mencapai jutaan orang, seakan menjawab pemberitaan BBC yang menganggap aksi 212 hanya kurang dari satu juta orang. Juga banyak tantangan yang dihadapi umat seperti kriminalisasi ulama, upaya-upaya penggembosan, penolakan, narasi buruk oleh media-media barat terhadap aksi 212 ini. Namun umat Islam tetap konsisten dan seakan-akan heroik. 


\section{DAFTAR PUSTAKA}

Rozie, F. (2016, 29 November). GNPF MUI: Peserta Demo 2 Desember Capai 3 Juta Orang, Liputan 6. Diakses dari https://www.liputan6.com/news/ read/2664951/gnpf-mui-pesertademo-2-desember-capai-3-juta-orang.

Amalia, U. (2018). Keberpihakan Media dalam Aksi 212: Analisis Framing Model Robert N. Entman terhadap Kolom Tajuk Aksi Damai 212 Harian Umum Republika. Diploma thesis, UIN Sunan Gunung Djati, Bandung.

Abdul, G. (2016, 16 November). Tentang Tafsir Surat Al Maidah 51 dan Ahok Jadi Tersangka, Bintang, Diakses dari https://www.bintang.com/lifestyle/ read/2653432/tentang-tafsir-surat-almaidah-51-dan-ahok-jadi-tersangka.

Zaelani, M. \& Santana, S. K. (2016). Konstruksi berita Aksi Damai 212: Analisis teks berita melalui Framing Robert N. Entman terhadap Aksi Damai 212 pada INews dan Metro TV. Prosiding Jurnalistik, 2, 180-185.

Gamson, W. A. \& A. Mogdiliani. 1989. Media discourse and public pendapaton on nuclear power: a constructionist approach. American Journal of Sociology, 95, 1-37.

Simanjuntak, R. A. (2016, 14 November). Perkataan Ahok Soal Al Maidah 51 Sudah Penuhi Unsur Penistaan Agama, Sindonews. Diakses dari https://metro. sindonews.com/read/1155126/170/ perkataan-ahok-soal-al-maidah51-sudah-penuhi-unsur-penistaanagama-1479096186.

Aziz, N (2017, 20 April). Ketika AniesSandi menang dengan kekuatan Islamis, BBC Indonesia. Diakses dari http://www.bbc.com/indonesia/ indonesia-39644574.

VOA-Islam. (2017, 2 Mei). Jika FPI dan HTI Melanggar Hukum, Tegakkan, Bukan Menuduh Meraka Anti Bhineka \&
Intoleran, VOA-Islam. Diakses dari http://www.voa-islam.com/read/ politik-indonesia/2017/05/04/50430/ jika-fpi-dan-hti-melanggar-hukumtegakkan-bukan-menuduh-merakaanti-bhineka-intoleran/\#sthash. ynzS95J6.dpbs.

Febrianti, H. L. (2017, 5 Desember). Kasus Pemberitaan Al-Maidah di Kompas \& Republika. Pusat Penelitian Kemasyarakatan $\mathcal{E} \quad$ Kebudayaan. Diakses dari http://pmb.lipi.go.id/ kasus-pemberitaan-al-maidah-dikompas-republika/

Kurnia, Z. A. (2017). Analisis framing pemberitaan mengenai "Aksi Damai Bela Islam 212" pada media online Kompas.com dan Republika Online. Undergraduate thesis, Universitas Muhammadiyah Yogyakarta, Yogyakarta.

Mahesa, W. P. (2017). Analisis framing pemberitaan Aksi Super Damai 212 di media online Kompas dan Republika. Undergraduate thesis, Universitas Pasundan, Bandung. 